\title{
ESTUDO DAS PROPRIEDADES DE RESINA À BASE DE POLIESTIRENO EXPANDIDO (EPS) APLICADA EM SUPERFÍCIES DE MADEIRA*
}

\author{
Gabriela Olsson Schneider ${ }^{1}$ \\ Paula Vieira Schwade 2 \\ Cristiane Krause Santin ${ }^{3}$ \\ Tatiana Louise Avila de Campos Rocha ${ }^{4}$
}

Resumo

Dentre os materiais que representam a crescente e alarmante quantia de resíduos sólidos gerados nos últimos anos, destacam-se polímeros como o poliestireno expandido (EPS), material largamente depositado no ambiente natural. Propõe-se, portanto, seu uso na composição de uma resina veículo para tinta, em adição ao óleo essencial de casca de laranja. Assim, estabelece-se o objetivo de avaliar as propriedades do fluido resultante e da película seca, incluindo sua interação com diferentes superfícies de madeira. Observa-se que a resina possui viscosidade elevada e tendência ao comportamento não-newtoniano pseudoplástico, bem como alta homogeneidade e mais de $95 \%$ de adesão a superfícies de pau-marfim. Avaliações da resina aplicada em MDF sugerem que se deve evitar a aplicação em faces fibrosas de blocos e placas deste tipo de madeira, dado que, ao contrário de sua superfície lisa, não há formação de revestimento visível mesmo após a aplicação sucessiva de três camadas de resina. Conclui-se que, considerando a aplicação de resina em superfícies lisas de madeira, há viabilidade técnica de produção de tinta a partir da resina veículo em estudo.

Palavras-chave: Poliestireno expandido; Polímeros; Casca de laranja; Tinta;

\section{STUDY OF THE PROPERTIES OF RESIN BASED ON EXPANDED POLYSTYRENE (EPS) APPLIED TO WOODEN SURFACES}

\section{Abstract}

Among the materials that represent the crescent and alarming amount of solid residues generated over the past years, polymers such as expanded polystyrene (EPS), a material largely deposited in the natural environment, are noteworthy. It is then proposed to use EPS in the composition of a vehicle resin for paint, in addition to essential oil of orange peel. Thus, it is established as purpose to evaluate the properties of the resulting fluid and the dry film, including its interaction with different wooden surfaces. It is observed that the resin's elevated viscosity demonstrates a tendency towards pseudoplastic non-newtonian behavior, as well as high homogeneity and over $95 \%$ of adhesion to pau-marfim surfaces. Evaluations of resin applied to MDF suggest that the application on the fibrous surfaces of MDF blocks and plaques should be avoided, given that, unlike its smooth surface, there is no formation of visible coating even after applying three layers of resin. Considering the application of resin is to be done on smooth wooden surfaces, it is concluded that it is technically viable to produce a paint based on the studied resin.

Keywords: Expanded polystyrene; Polymers; Orange peel; Paint.

1 Engenharia Química, estudante de graduação, Escola Politécnica, Universidade do Vale do Rio dos Sinos, São Leopoldo, Rio Grande do Sul, Brasil.

2 Engenharia Química, estudante de graduação, Escola Politécnica, Universidade do Vale do Rio dos Sinos, São Leopoldo, Rio Grande do Sul, Brasil.

3 Graduação e Mestrado em Química, Doutorado Ciência dos Materiais, Professor, Universidade do Vale do Rio dos Sinos (Unisinos), São Leopoldo, Rio Grande do Sul, Brasil.

4 Graduação Química Industrial, Mestrado Engenharia de Materiais, Doutorado Ciência dos Materiais, Coordenação Engenharia de Materiais, Universidade do Vale do Rio dos Sinos (Unisinos), São Leopoldo, Rio Grande do Sul, Brasil. 


\section{INTRODUÇÃO}

Embora tenham sido elaborados planos e metas ambientais como a Política Nacional de Resíduos Sólidos, a geração destes resíduos no Brasil cresce anualmente, e a sua reciclagem não é suficiente para suportar o lixo produzido. Sabe-se, por exemplo, que a geração total de resíduos sólidos no país durante 2014 foi 2,9\% maior que o ano anterior, totalizando 78,6 milhões de toneladas de resíduos gerados [1]. Dentre os materiais que compõem este número alarmante, destacam-se polímeros como o poliestireno expandido (EPS), conhecido no Brasil pela marca Isopor ${ }^{\circledR}$. O EPS tornou-se muito utilizado na construção civil, entre outras aplicações, em decorrência de possuir propriedades isolantes, resistência mecânica, leveza, facilidade de manuseio e baixo custo. Ainda, os produtos finais de EPS têm potencial para serem completamente reaproveitados e reciclados, podendo retornar à condição de matéria-prima [2]. Entretanto, somente $34,5 \%$ do total de EPS produzido em 2014 foi reciclado, de modo que foram depositadas 25.770 toneladas em ambiente natural (ABIQUIM, 2014). Assim, torna-se necessário encontrar métodos inovadores de reutilização do EPS pós-consumo.

Ainda no contexto da obtenção de matéria-prima a partir de resíduos, têm potencial para aproveitamento também os rejeitos da produção de sucos de laranja no Brasil. Considerado o maior exportador mundial deste suco em 2011, o Brasil exportou 1,5 milhão de toneladas, superando em mais de $200 \%$ o segundo colocado no mesmo ranking [3]. São resíduos desta produção cerca de $50 \%$ do peso total da fruta na forma de polpa e casca, cujo destino final é, usualmente, a alimentação animal e a queima. Nas glândulas da superfície externa da casca, no entanto, é armazenado um óleo essencial composto majoritariamente por Dlimoneno, um hidrocarboneto terpênico moderadamente utilizado como fluido refrigerante secundário, componente de produtos de limpeza e solvente na indústria de tintas [4]. Este óleo essencial pode ser extraído de diferentes formas, dentre as quais destaca-se a prensagem a frio [5].

No ano de 2008, o volume produzido de tintas e o faturamento total desta indústria no Brasil o tornaram um dos cinco maiores países ocidentais produtores de tintas. No entanto, o país ainda é um grande mercado potencial de tintas e correlatas, dada a possibilidade de crescimento do consumo per capita. Tinta é uma composição líquida, geralmente viscosa, constituída de um ou mais pigmentos dispersos em um aglomerante líquido que, estendida em película fina, forma um filme opaco e aderente ao substrato, cuja finalidade é proteger e embelezar as superfícies [6].

As resinas normalmente utilizadas em tintas convencionais são translúcidas ou transparentes quando se convertem em películas finas sólidas. Em uma tinta, os responsáveis pela opacidade são os pigmentos, capazes de ocultar a superfície sobre a qual a tinta foi aplicada. Esta capacidade do pigmento é chamada de "poder de cobertura". Ainda, as resinas geralmente são líquidos viscosos ou soluções viscosas de sólidos em solventes. Quando os pigmentos são adicionados durante a produção da tinta, a viscosidade aumenta ainda mais. A viscosidade é importante na fabricação e deve ser alta como uma pasta, para facilitar o trabalho de dispersão e moagem dos pigmentos [6]. $\mathrm{Na}$ análise de polímeros fundidos, quando a viscosidade do polímero em escoamento diminui com o aumento da taxa de cisalhamento, diz-se que o polímero apresenta comportamento nãonewtoniano pseudoplástico, classificação mais comum em polímeros fundidos [7]. Considera-se comum, também, que tintas apresentem este mesmo comportamento.

A fim de viabilizar o uso de EPS e solvente natural extraído da casca de laranja na produção de uma tinta, realizou-se um estudo prévio de diversas formulações de resina veículo para tinta, e observou-se excelente desempenho da formulação dita F14, composta por EPS, Dlimoneno e $4 \%$ do copolímero SEBS como plastificante [8].

Sendo assim, assume-se como objetivo do presente estudo, a adaptação e reavaliação da resina $\mathrm{F} 14$ através de análises físico-químicas e microscópicas, comparando seu desempenho como revestimento de diferentes superfícies de madeira e viabilizando seu uso como veículo na produção de tinta à base de EPS e solvente natural. 


\section{MATERIAIS E MÉTODOS}

\subsection{Elaboração de resina}

A resina elaborada é uma adaptação da resina F14 [8]. A resina atualmente em estudo difere da anterior somente pela substituição do D-limoneno por óleo essencial de laranja orgânico comercial extraído por prensagem a frio.

\subsection{Avaliação de viscosidade}

Utilizou-se o viscosímetro rotacional Brookfield (modelo LVDV-II-Pro) para avaliar a viscosidade da resina. O equipamento opera efetuando a leitura do torque produzido pelo movimento de uma ponta de prova de geometria conhecida (spindle SC4-31) que gira no meio fluido resinoso contido em um compartimento removível e encamisado cuja temperatura é mantida em torno de $25^{\circ} \mathrm{C}$ por banho termostatizado. Com auxílio do software Rheocalc, obtém-se valores de viscosidade aparente e tensão de cisalhamento em função de dez taxas de deslocamento distintas.

Cabe salientar que a análise propriamente dita é realizada somente após a obtenção de uma curva de testes, na qual a velocidade angular sofre grandes variações. Isto é realizado a fim de diagnosticar qual a faixa de velocidades em que o equipamento consegue operar sem atingir porcentagens de torque insuficientes ou excessivas, que poderiam comprometer a confiabilidade dos resultados.

Busca-se, ainda, caracterizar o comportamento da resina a fim de verificar se há reprodução do comportamento adequado à dispersão de pigmentos na produção de tinta.

\subsection{Preparação dos corpos de prova de madeira}

Foram utilizados dois tipos distintos de madeira, pau-marfim e MDF. Ambos os substratos foram preparados para a aplicação de resina de modo que a superfície a ser pintada estivesse limpa, seca e lixada, isenta de partículas soltas, livre de impurezas como gordura e ferrugem, bem como restos de pintura antiga e pó. Na execução do lixamento, utilizam-se sucessivamente lixas de gramatura 220, 400 e 600 para nivelar a superfície. Durante as aplicações, utiliza-se uma lixa média (gramatura 400) para auxiliar na abertura dos poros do material, facilitando a aderência da camada sequente do revestimento [9].

\subsection{Aplicação de resina}

Fez-se a aplicação da resina formulada em corpos de prova conforme os tipos de madeira mencionados. No entanto, optou-se por aplicar resina na superfície lisa do MDF e, também, nas laterais fibrosas de placas da mesma madeira. Foram, ainda, produzidas amostras de madeira revestida com uma, duas ou três camadas de resina, totalizando nove amostras distintas entre si.

As aplicações foram feitas com pincel, de modo a mergulhar apenas $2 / 3$ do comprimento dos pelos na resina. Leva-se o pincel à superfície dos corpos de prova com uma pequena inclinação do pincel para favorecer 0 deslizamento. $O$ espalhamento é efetuado de maneira uniforme, nivelando e alisando as camadas por meio de longas pinceladas cruzadas sobre as iniciais. 


\subsection{Avaliação da compatibilidade}

Avalia-se a compatibilidade entre os componentes da resina através da observação da superfície do filme aplicado sobre a madeira e sequente identificação de pontos de separação de fases. Para este efeito, considera-se evidência de incompatibilidade a existência de regiões acometidas por uma rugosidade significativa ou mudanças de coloração.

\subsection{Teste de adesão à superfície}

A adesão é um critério cuja importância está associada ao impedimento de fenômenos indesejados a que o filme pode ser submetido, tais como descascamento e formação de bolhas de ar e de umidade, que deterioram a película. A avaliação desta propriedade consiste na execução de cortes superficiais, em grade, na face do bloco revestida por resina, formando 25 quadrados $(2 \mathrm{~mm} \times 2 \mathrm{~mm})$ sobre o filme, e na colocação de uma fita com adesividade de $25 \mathrm{~g} / \mathrm{cm}^{3}$ sobre a grade, mantendo-a aderida durante um minuto. Em seguida, retira-se a fita e analisa-se a fração do filme representada pela área destacada da película, obtendo resultados percentuais [10]. O procedimento é descrito na Figura 1.

Figura 1. Esquema representativo da avaliação de adesão ao substrato.

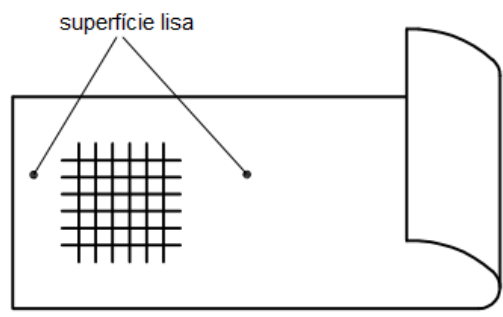

Posição do adesivo em relação ao corte em grade

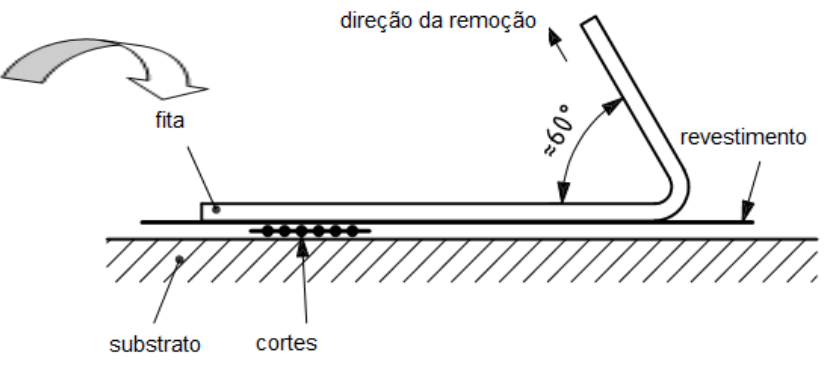

Posição imediatamente anterior à remoção do adesivo

Adaptado de ISO 2409.

\subsection{Corte das placas de madeira}

Os corpos de prova já revestidos pela resina foram cortados utilizando uma serra disco. Os cortes foram efetuados em direção ortogonal à aplicação do filme, de modo a expor a região interna dos blocos de madeira.

\subsection{Análise da interação resina-superfície}

As amostras foram observadas utilizando um Microscópio Digital USB (com ampliação entre 50x e 500x) e o software Plugable Viewer. Foi efetuada uma marcação sobre a superfície exposta após o corte dos corpos de prova, a fim de se obter uma escala nas imagens e determinar a espessura aproximada do filme ou a profundidade de penetração de resina na madeira, caso houver. A marcação consistiu no traçado de um pequeno sinal a cada milímetro, utilizando um escalímetro de desenho e grafite de espessura $0,3 \mathrm{~mm}$. 


\section{RESULTADOS E DISCUSSÃO}

\subsection{Avaliação de viscosidade}

Os resultados obtidos são expressos nas curvas da Figura 2, nas quais consta a relação de dez medidas de viscosidade aparente e tensão de cisalhamento em função de diferentes taxas de deslocamento do fluido.

Figura 2. Tensão de cisalhamento e viscosidade em função da taxa de deformação do fluido.

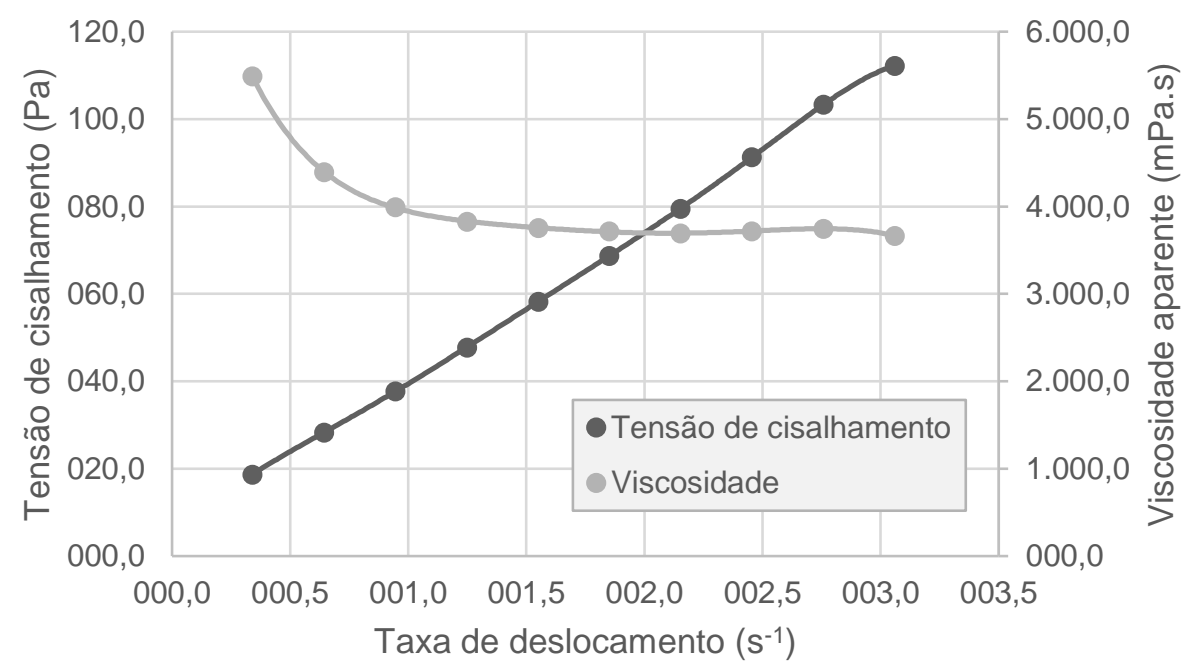

Nota-se que há um decréscimo de viscosidade aparente, ao passo que aumenta a tensão de cisalhamento, o que sugere uma tendência da resina estudada ao comportamento de um fluido não-newtoniano pseudoplástico. Sabendo que esta classificação é característica não somente de polímeros fundidos como também de tintas em geral e que foram encontradas viscosidades bastante elevadas, estes resultados parciais sugerem que a viscosidade da resina seja adequada à dispersão de pigmentos e aditivos, viabilizando a produção de tinta com alto poder de cobertura.

\subsection{Avaliação de compatibilidade}

Verificou-se uma leve rugosidade no filme de resina mesmo quando aplicado sobre superfícies lisas, o que infere uma sutil separação de fases durante a evaporação de solvente e secagem da película. A resina, embora translúcida, mostrou-se levemente alaranjada em decorrência do solvente utilizado, que possui a mesma coloração. No entanto, não foram encontrados quaisquer sinais de incompatibilidade ou desprendimento da superfície indicados por uma mudança na coloração, tais como esbranquiçamentos no filme.

\subsection{Análise da interação entre a resina e a superfície}

A observação das imagens permite analisar as amostras segundo dois critérios distintos: a influência da rugosidade da superfície na formação de película e o acúmulo de resina em cada camada. 
Naturalmente, observou-se que a espessura da película aumenta proporcionalmente conforme são acrescidas camadas de resina uma sobre a outra. A Figura 3 evidencia a diferença de espessura da película sobre superfícies lisas de MDF.

Figura 3. Espessura da película de resina sobre a superfície lisa de MDF com (a) 1 aplicação, (b) 2

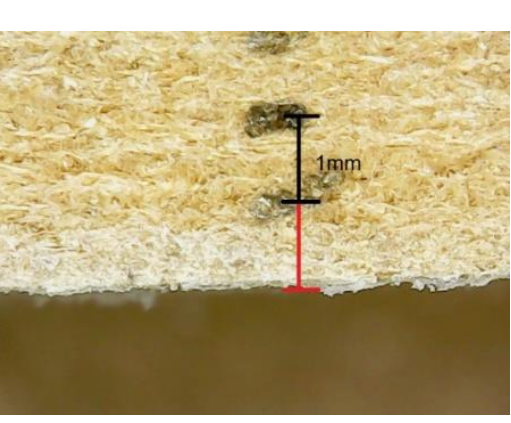

(a) aplicações e (c) 3 aplicações.

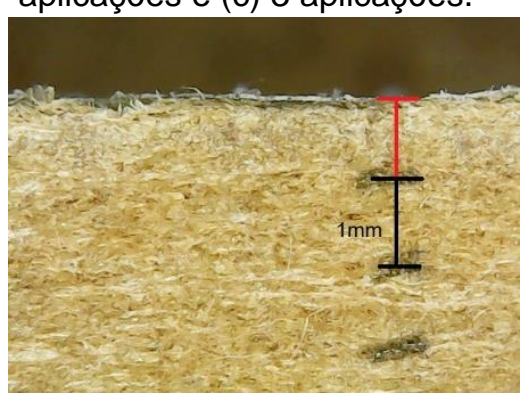

(b)

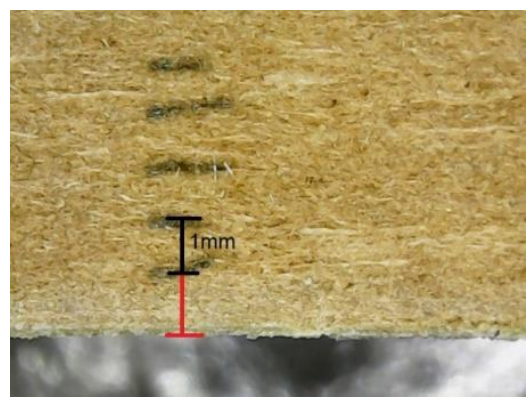

(c)

O comportamento nas outras superfícies foi bastante semelhante ao da Figura 3 no sentido de que o acréscimo de camadas de resina promove a formação de filme mais espesso. No entanto, as superfícies possuem rugosidades bastante distintas, e isto se reflete na película formada, como evidenciado na Figura 4.

Figura 4. Espessura da película de 3 aplicações de resina (a) sobre a superfície fibrosa de MDF e (b)

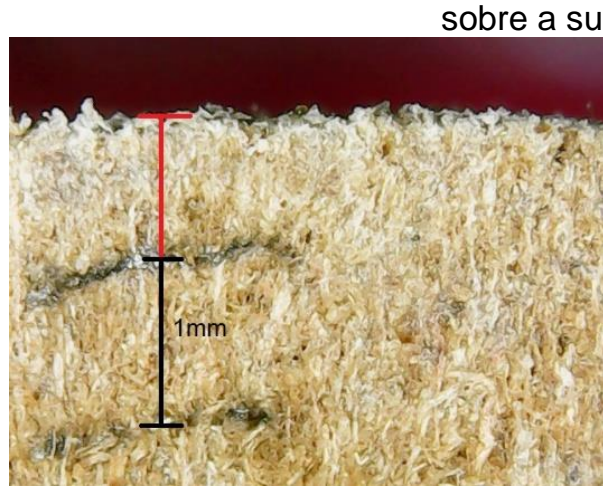

(a)

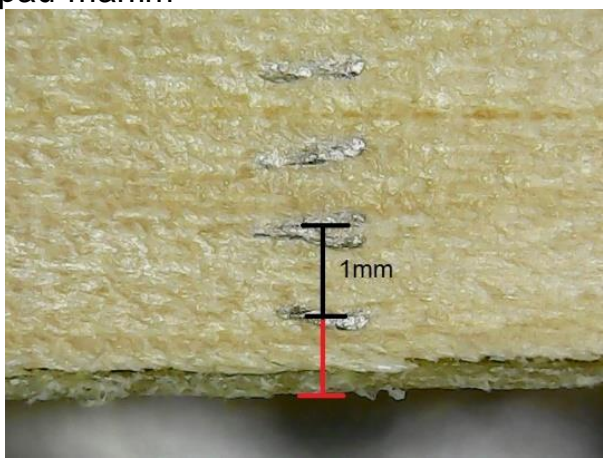

(b)

Desse modo, percebe-se que as películas formadas na superfície lisa de MDF e em pau-marfim são bastante semelhantes, enquanto a superfície fibrosa de MDF apresenta filme muito fino. Aparentemente, o filme formado foi tão fino quanto aquele observado na superfície lisa de MDF após a aplicação de somente uma camada de resina. Infere-se que a ausência de filme visível na superfície seja consequência da penetração da resina pelos espaços vazios entre as fibras, ou, ainda, que o revestimento das fibras ocorre em todo o seu entorno, uma a uma, diferentemente das superfícies mais lisas, cujas fibras orientadas paralelamente entram em contato com a resina somente na parte superior.

Desse modo, considera-se inviável a aplicação de resina nesta superfície, o que impossibilita o uso desta resina e da tinta que ela compõe para revestir placas de MDF cuja face fibrosa estiver exposta. 


\subsection{Teste de adesão}

O teste de adesão foi efetuado na superfície de madeira pau-marfim. A região de corte pode ser observada na Figura 5, onde tornam-se evidentes 0 esbranquiçamento das regiões próximas ao corte e a ocorrência de um desprendimento da resina nestes mesmos locais, reiterando a correlação estabelecida entre estes aspectos.

Figura 5. Corte no filme da resina aplicada à superfície de pau-marfim.

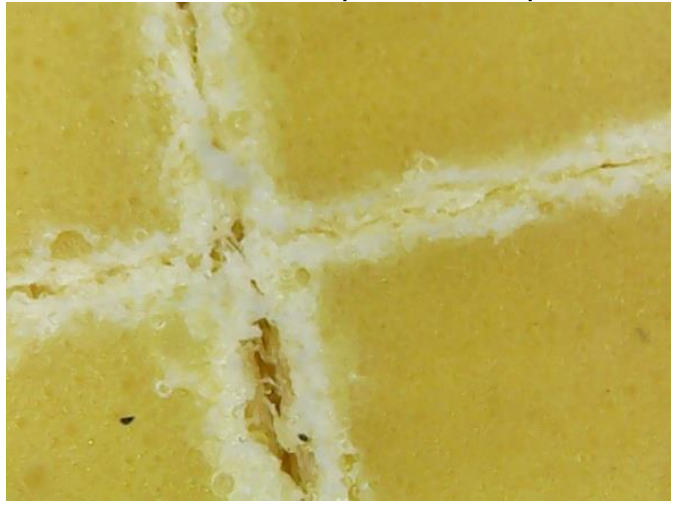

Observou-se que mais de $95 \%$ da resina permaneceu aderida à superfície do corpo de prova após a execução do teste. Este desempenho é avaliado como satisfatório em tintas e, portanto, considera-se tecnicamente viável a utilização desta resina na produção de tinta.

\section{CONCLUSÃO}

Os resultados demonstram grande compatibilidade entre os componentes da resina dada a ausência de sinais de heterogeneidade na película aplicada À madeira paumarfim. A avaliação de viscosidade sugere uma tendência da resina ao comportamento não-newtoniano pseudoplástico, característico de polímeros fundidos e tintas. Observou-se, ainda na avaliação desta propriedade, que a viscosidade da resina foi bastante elevada, e, portanto, espera-se que seja facilitado o trabalho de dispersão e moagem dos pigmentos, promovendo um elevado poder de cobertura da tinta que será produzida.

É possível concluir, também, que a madeira pau-marfim, além de promover elevada adesão da resina à superfície, é a alternativa mais favorável à formação de filme de resina dentre os tipos de madeira em estudo. Isto se dá porque a madeira de MDF possui superfícies mais fibrosas nas laterais dos blocos compensados e, embora haja também faces lisas nestes blocos, a aplicação da resina em MDF exigiria maior seletividade. Além disso, o uso de blocos ou placas de MDF com espessura considerável poderia ocasionar um revestimento de má qualidade, uma vez que as fibras presentes nas laterais seriam revestidas por camadas mais finas de resina, sem que se formasse película visível.

\section{Agradecimentos}

Os autores agradecem ao CNPq e FAPERGS. 


\section{REFERÊNCIAS}

1 ABRELPE - Associação Brasileira de Empresas de Limpeza Pública e Resíduos Especiais. Disponível em: <www.abrelpe.org.br>. Acesso em: 08 de abril de 2016.

2 ABRAPEX - Associação Brasileira de Poliestireno Expandido. Disponível em: $<$ www.abrapex.com.br>. Acesso em: 08 de abril de 2016.

3 Food and Agriculture Organization of the United Nations Statistics - FAOSTAT. Trade of Crops and Livestock Products. Disponível em: <http://faostat3.fao.org/browse/T/TP/E>. 2012. Acesso em 31 mar. 2015.

4 Florida Chemical. What is d-limonene?. Disponível em: < http://floridachemical.com/whatisd-limonene.htm>. 2012. Acesso em: 31 mar. 2015.

5 Fernandes IJ, Kieling AG, Brehm FA, Agosti A, Moraes CAM. Avaliação da Extração de Óleo Essencial do Resíduo Casca de Laranja. 4ํㅜórum Internacional de Resíduos Sólidos. 2013.

6 Fazenda JMR. Tintas - Ciência e Tecnologia. 4 ed. São Paulo: Blucher; 2009.

7 Bretas RES, D’Ávila MA. Reologia de polímeros fundidos. 2 ed. São Carlos: EdUFSCar, 2010.

8 Schneider GO, Schwade PV, Santin CK, Rocha TLAC. Desenvolvimento de resina à base de poliestireno expandido (EPS) residual. 70ํㅡㄹ Congresso Anual ABM Week, 2015.

9 Associação Brasileira de Normaa Técnicas, ABNT NBR 13245 -Tintas para construção civil - Execução de pinturas em edificações não industriais -Preparação de superfície, São Paulo: 2011.

10 International Organization for Standardization, ISO 2409 - Paints and varnishes Cross-cut test, Geneva: 2010. 